\title{
INDIRECT TENSILE STRENGTH METHOD FOR DEFINING A PROPER PRACTICE OF ASPHALT MIXTURES DESIGN
}

\author{
ROSA VEROPALUMBO, NUNZIO VISCIONE \& FRANCESCA RUSSO \\ Department of Civil, Construction and Environmental Engineering, University of Naples Federico II, Italy
}

\begin{abstract}
This paper shows the results of a laboratory investigation of indirect tensile strength test effects on bituminous mixtures characterization. In particular, the research focusses, in the first analysis, on the procedure of Marshall mix design, where 4 different mixtures of hot mix asphalt (HMA) were prepared at different bitumen contents between $3.5 \%$ and $4.25 \%$ by total aggregate weight at $0.25 \%$ increments. In the second phase, bituminous specimens made-up by gyratory compactor in compliance with Marshall optimization were tested to evaluate their indirect tensile strength. It was ascertained how the air voids percentage and indirect tensile strength can change by varying the number of revolutions during gyratory compaction and the height of specimens. A one-way ANOVA test was finally carried out to verify whether statistically significant differences exist in terms of mechanical properties when the number of revolutions and the specimen size change. This research may help to provide administrations with fast laboratory procedures to use in situ for all activities related to acceptance of mixtures.
\end{abstract}

Keywords: specimens size, gyratory method, number of revolutions, indirect tensile strength.

\section{INTRODUCTION}

The bituminous mixtures adopted in road construction are subject to repetitive loads corresponding to the continuous passage of vehicles; such tons, if sufficiently high, cause the loss of stiffness of the materials constituting the package and can lead to cracking and breakage, through the accumulation of stresses in the long term. In general, the superstructure performs three different tasks:

- It reduces the stresses transmitted to the soil to a level compatible with its bearing capacity so that the ground does not suffer deformation.

- It forms a structure that is stable over time and not very deformable, able to withstand repeated loads applied by vehicles and such as to ensure adequate driving comfort.

- It guarantees traffic safety in relation to problems of tire-pavement adherence in the presence of weather agents (rain, mud, snow, ice, rubber deposits).

In reference to the second point listed above, in a flexible pavement an important role is played by a base layer to ensure a suitable structure of resistance. The base layer of flexible pavements is constituted of bituminous mixture with nominal aggregate size typically less than those of a subgrade layer. This layer aims to resist fatigue phenomena because it is an inflected layer, so it is mainly subjected to tensile stresses.

For this reason, it is fundamental to choose the right materials and make a good mix design of asphalt mixture to improve the performance of the pavement and for the increment of pavement useful life.

Some studies [1] have shown that the principal factor influencing the strength of bituminous mixture is the filler and in particular the type of filler adopted. Researchers have been studying the reemployment of second raw materials [2]-[4] such as the digested spent bentonite filler. They have shown that the use of this alternative material as filler in hot mix 
asphalt (HMA) mixture increases by about 7\% the indirect tensile strength (ITS) value if compared to the traditional mixture. Also, the use of waste brick powder [5] as mineral filler in asphalt mixture has been studied. The results have shown that the recycled brick fillers (at $40^{\circ} \mathrm{C}$ ) increase the stiffness modulus of asphalt binder which may improve the rutting resistance of asphalt mixture. Other types of filler such as steel slag, ladle furnace slag, waste foundry sand, glass wastes and coal ash [6] have been reemployed in cement concrete mixtures for base and sub-base layers in road pavement using the ITS value to complete the mix design of the mixtures.

In reference to the potential of fine aggregates recycled in powder form as fillers in the bituminous mixture, other researchers [7] have focused their studies on the use of such materials for the base layers and foundation. The traditional Marshall procedure was used for the mix design of mixtures and by the analysis of results it was concluded that mixtures containing recycled fine aggregates in powder have a higher indirect tensile strength and a higher fatigue strength than the traditional mixtures. An effective method is also provided to better understand the internal structure shape after fatigue damage [8] and the influence of microstructure characteristics on fatigue performance. The analysis of results has shown that the air-void ratio increases after fatigue damage at different test temperatures. Therefore, the rising temperature is harmful to the fatigue performance over low temperature range from $-10^{\circ} \mathrm{C}$ to $10^{\circ} \mathrm{C}$. As has been seen, the indirect tensile strength test is the primary test carried out to characterize the stiffness of a bituminous mixture. Most frequently, the problem is to find if the specimens compaction type used for ITS evaluation during the mix design phase is also valid during the control phase of the mixture. The purpose of this research was to offer claims and references for mixture packaging process with 100\% limestone aggregates for a base layer, evaluating the behaviour and the changes of some mechanical properties such as Marshall Stability and Indirect Tensile Strength. In particular the research aims to evaluate ITS on mixtures optimized with the right percentage of bitumen according to Technical Rules of the Contract not only compacted with impact compaction but also replicated using another type of compaction method such as gyratory compaction in an effort to obtain the same value.

\section{MATERIALS AND METHOD}

\subsection{Aggregates}

In this study traditional limestone aggregates were used for the mix production. The limestone material is the product of limestone crushing [9] and it is configured as a different size aggregate white in colour and characterized by an amorphous structure. The limestone aggregates have been selected because it is one of the most suitable materials for the HMA production for a base layer in Italy. The chemical properties have been evaluated according to EPA 7000B-2007 (Table 1) and results shown that this type of material is constituted (main properties) by calcium (66\%), steel (4.2\%), silicon (26\%) and magnesium $(2.7 \%)$.

Table 1: Chemical properties of limestone aggregates.

\begin{tabular}{|l|c|c|}
\hline Parameters & Unit & Value \\
\hline Calcium & $\mathrm{mg} / \mathrm{kg}$ & 190000 \\
\hline Steel & $\mathrm{mg} / \mathrm{kg}$ & 12000 \\
\hline Silicon & $\mathrm{mg} / \mathrm{kg}$ & 75000 \\
\hline Magnesium & $\mathrm{mg} / \mathrm{kg}$ & 7800 \\
\hline
\end{tabular}


The physical properties of limestone aggregates samples were evaluated, and the results are reported in Table 2.

Table 2: Aggregate physical properties.

\begin{tabular}{|l|c|c|c|}
\hline Aggregate test & Unit & Value & Standard \\
\hline Los Angeles abrasion value & $\%$ & 20.4 & UNI EN 1097-2 \\
\hline Shape index & - & 70.7 & UNI EN 933-4 \\
\hline Flakiness index & - & 89.0 & UNI EN 933-3 \\
\hline
\end{tabular}

\subsection{Bitumen}

A standard 50/70 penetration grade bitumen was used as binder, most commonly used in Italy for traditional HMA mixtures. Preliminary evaluation of the collected asphalt samples was conducted to verify that the significant properties are compliant with the specifications of the National Italian Autonomous Roads Corporation for a fresh binder (Table 3).

Table 3: Properties of asphalt 50/70 pen binder.

\begin{tabular}{|l|c|c|c|}
\hline Test & Unit & Value & Standard \\
\hline Penetration @ $25^{\circ} \mathrm{C}$ & $\mathrm{dmm}$ & 61 & UNI EN 1426 \\
\hline Soft. point & ${ }^{\circ} \mathrm{C}$ & 48.8 & UNI EN 1427 \\
\hline Dynamic Visc. @ $160^{\circ} \mathrm{C}$ & $\mathrm{Pa} \mathrm{s}$ & 0.22 & UNI EN 13702 \\
\hline Frass & ${ }^{\circ} \mathrm{C}$ & -10 & UNI EN 12593 \\
\hline
\end{tabular}

An additional test was conducted to evaluate the viscoelastic properties of the bitumen, in

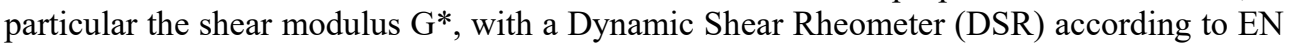
14770 Standard. The bitumen samples were tested at 5 different temperatures $\left(10^{\circ} \mathrm{C}, 20^{\circ} \mathrm{C}\right.$, $30^{\circ} \mathrm{C}, 40^{\circ} \mathrm{C}, 50^{\circ} \mathrm{C}$ ) and in a frequency range of $0.1-10 \mathrm{~Hz}$. The test consists to bring the test specimen to the selected gap setting plus from $0.025 \mathrm{~mm}$ to $0.050 \mathrm{~mm}$ for parallel plate geometries and applied a constant oscillating stress.

To represent the behaviour of the binder in function of the temperature and frequency, the $\mathrm{G}^{*}$ obtained are reported in terms of Master curve (Fig. 1), developed on the bases of Williams-Landel-Ferry (WLF) law:

$$
\log \frac{a(T)}{a\left(T_{0}\right)}=\frac{-C_{1} \cdot\left(T-T_{0}\right)}{C_{2}+T-T_{0}}
$$

where $a(T)$ and $a\left(T_{0}\right)$ are the shift factors at temperature $T$ and $T_{0}$; $T$ is the temperature to shift; $\mathrm{T}_{0}$ is the temperature of reference for the shift; and $\mathrm{C}_{1}$ and $\mathrm{C}_{2}$ are constants that depend by nature of the material. 


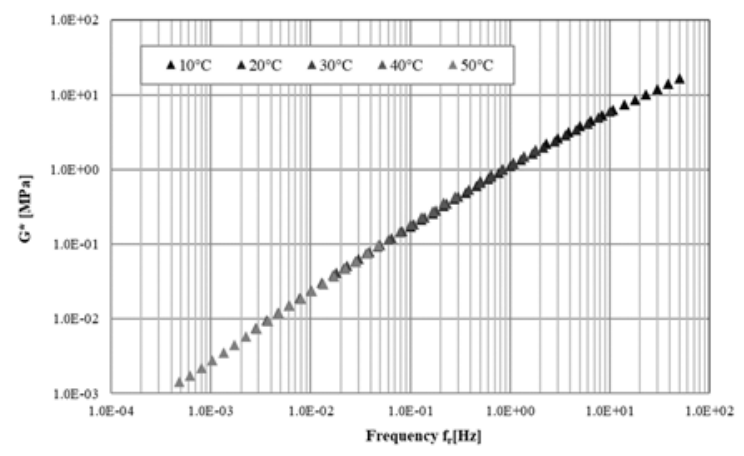

Figure 1: Master curve.

\subsection{Mix design}

\subsubsection{Grading curve}

The particle size distribution of aggregates is one of the most important characteristics to determine how it will perform as a pavement material. In this research the grading curve study was established in accordance with several local and international requirements as follows:

- According to EN13108-1 (see Table 1 in EN 13108-Overall limits of target composition - basic sieve set plus set 2).

- According to Technical Specifications on road maintenance of the National Italian Autonomous Roads Corporation that reflects EN 13108-1 but it is more restrictive regarding the calculation of the percentage of material passing through some specific sieves.

- According to maximum density gradation obtained using $\mathrm{n}=0.45$ in the equation developed by Fuller and Thompson in 1907.

The aggregates mixture was produced in a laboratory using different sizes of limestone adequately proportioned - and the optimal distribution obtained is reported in Table 4 and Fig. 2.

Table 4: Aggregate size proportion.

\begin{tabular}{|c|c|}
\hline $\begin{array}{c}\text { Sieve size } \\
\text { (mm) }\end{array}$ & $\begin{array}{c}\text { Passing } \\
(\mathbf{\%})\end{array}$ \\
\hline $\mathbf{0 . 0 6 3}$ & 7.2 \\
\hline $\mathbf{0 . 2 5}$ & 10.6 \\
\hline $\mathbf{0 . 5}$ & 12.5 \\
\hline $\mathbf{2}$ & 21.7 \\
\hline $\mathbf{6 . 3}$ & 38.0 \\
\hline $\mathbf{1 0}$ & 56.9 \\
\hline $\mathbf{1 4}$ & 70.7 \\
\hline $\mathbf{2 0}$ & 89.0 \\
\hline $\mathbf{3 1 . 5}$ & 100.0 \\
\hline
\end{tabular}




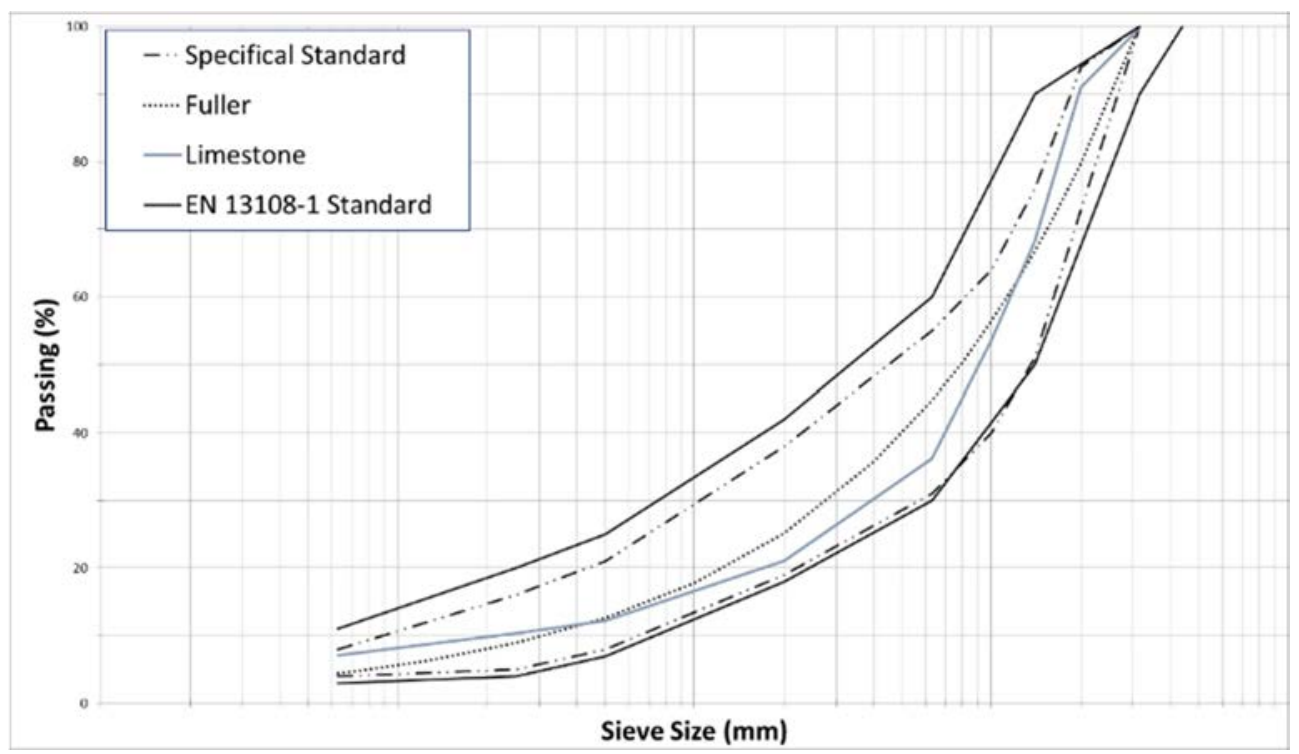

Figure 2: Grading curve of limestone aggregates.

\subsubsection{Optimal bitumen content}

The optimal bitumen content has been evaluated according to Marshall method. This method is based on the volumetric approach of design mix materials. Though, all the volumetric parameters are important and required to be within the allowable limit to have better performance of the HMA, the bitumen content and percentage air voids plays a dynamic role in the durability of the HMA. The Marshall method seeks to select the asphalt binder content at a desired density that satisfies minimum stability and range of flow values required by technical standards. Different 4 HMA mixtures were prepared at 4 different bitumen contents between $3.5 \%$ and $4.5 \%$ by total aggregate weight at $0.25 \%$ increments for the bituminous mixture design solutions according to Technical Specifications on road maintenance of the National Italian Autonomous Roads. Sixteen cylindrical specimens (4 for each HMA mixture) with a diameter of $101.6 \pm 0.1 \mathrm{~mm}$ and a height of $63.05 \pm 2.5 \mathrm{~mm}$ were prepared according to UNI EN $12697-30$ using a sliding mass of $7850 \pm 50 \mathrm{~g}$ falling from a height of $457 \pm 5 \mathrm{~mm}$ with 75 blows on each side. For every specimen packaged, volumetric properties [10] have been evaluated according to UNI EN 12697-8 (dimensional and SSD procedure) and at the same time mechanical performances in terms of Marshall Stability and Flow have been evaluated according to UNI EN 12697-34 to determine the optimal bitumen content. The optimum binder content has been selected based on the combined results of Marshall stability and flow and voids analysis according to requirements of the National Italian Autonomous Roads Corporation specification.

The optimal bitumen content (Fig. 3) has been reached in correspondence of $4.00 \%$ on total weight of aggregates to which corresponds a stability value of $818 \mathrm{~kg}$; flow value of $2.65 \mathrm{~mm}$ and a percentage of SSD and dimensional voids respectively of $4.4 \%$ and $11.1 \%$. 


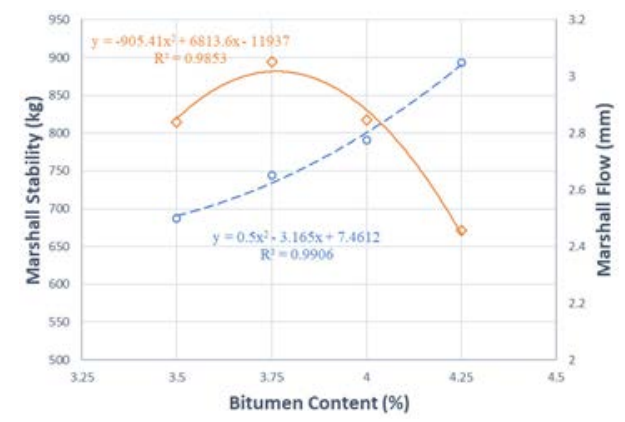

(a)

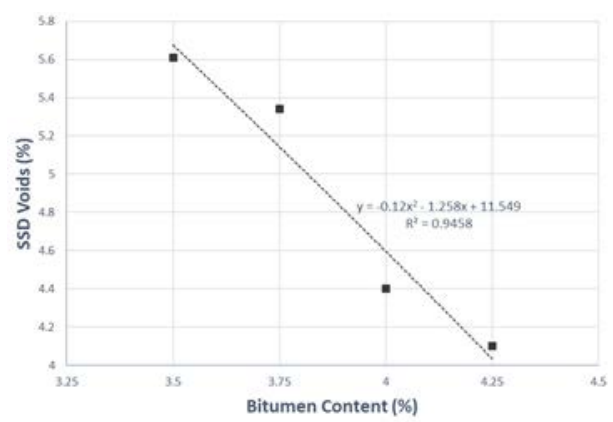

(b)

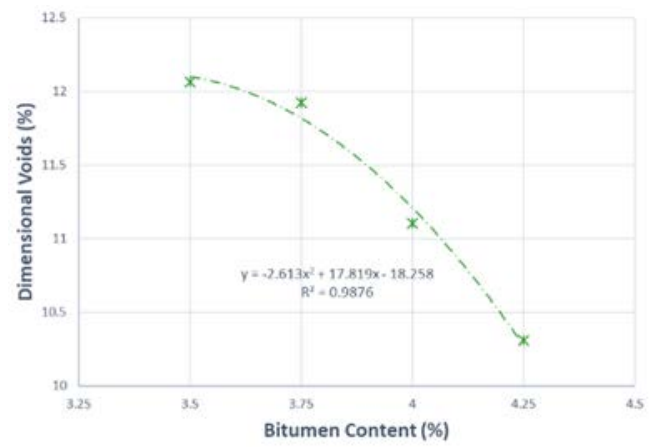

(c)

Figure 3: Bitumen content. (a). Marshall stability and Marshall flow; (b) SSD voids; (c) Dimensional voids.

\subsection{ITS evaluation}

The effect of traffic load in a long period could be affect the strength of an asphalt mixture showing fatigue cracks and/or rutting. To determine this damage is commonly used the Indirect Tensile Strength (ITS). The ITS test was performed according to UNI EN 12697-23. To evaluate the ITS, the cylindrical specimen must be placed in the compression testing machine between the loading strips and be loaded diametrically along the direction of the cylinder axis with a constant speed of displacement until it breaks. The indirect tensile strength is the maximum tensile stress calculated from the peak load applied at break and the dimensions of the specimen according the following eqn:

$$
I T S=\frac{2 P}{\pi D H},
$$

where ITS is the indirect tensile strength, expressed in gigapascals (GPa); $P$ is the peak load, expressed in kilonewtons $(\mathrm{kN}) ; D$ is the diameter of the specimen, expressed in millimetres $(\mathrm{mm})$; and $H$ is the height of the specimen, expressed in millimetres ( $\mathrm{mm})$.

Besides the strength of mixture is also compromised by water effect thus to evaluate its behaviour and durability the ITS value was determinate before and after a soaked in a water bath for $72 \mathrm{~h}$ at $40^{\circ} \mathrm{C}$. The relation of the strength values before and after water storage is called 
Indirect Tensile Strength Ratio according to UNI EN 12697-12 standard. Therefore, the following eqn has been adopted:

$$
I T S R=\frac{I T S_{w e t}}{I T S_{d r y}} \cdot 100
$$

where ITSR is the indirect tensile strength ratio (\%); ITS $S_{\text {wet }}$ is the average indirect tensile strength of the wet group $(\mathrm{kPa})$; and ITS $S_{d r y}$ is the average indirect tensile strength of the dry group $(\mathrm{kPa})$.

\section{RESULTS AND DISCUSSION}

One of the most difficult problem that incur in the pavement world, in particular during the control phase of mixture is choosing the correct size of the specimen for ITS evaluation. For this reason, the research in exam deals with specimen compacted with Marshall compactor and also with specimens obtained with the gyratory compactor according to UNI EN 1269731 at different size because the gyratory standard prescribe a range of height different from those required by ITS standard which requires that the specimens shall be compacted in accordance to UNI EN 12697-31.

Therefore, in this research the ITS parameter was evaluated on:

- Specimens packaged according to UNI EN 12697-30 with a diameter (101.6 \pm 0.1$)$ $\mathrm{mm}$ and height $(63.5 \pm 2.5) \mathrm{mm}$.

- Specimens packaged according to UNI EN 12697-31 with a diameter of $150 \mathrm{~mm}$ (maximum aggregate size is more than $16 \mathrm{~mm}$ ) using a height falling within the range defined by ratio between $h_{\min }$ and the diameter $\mathrm{D}$ of 0.66 to 1.05 .

- Specimens packaged according to UNI EN 12697-23 with a diameter of $150 \mathrm{~mm}$ (maximum aggregate size not exceed $40 \mathrm{~mm}$ ) and a height of between $35 \mathrm{~mm}$ and $75 \mathrm{~mm}$.

The evaluation of ITS, at the optimum bitumen content obtained using Marshall mix design method, has been evaluated on specimens compacted using the gyratory compactor. Furthermore, by means of the gyratory compactor, the asphalt mixtures have been designed at a specific level of compactive effort, that is a function of the number of gyrations $\mathrm{N}_{\text {design. }}$. Two different numbers of gyrations have been chosen (100 and 180) to have an air voids correlation with Marshall specimen. To comply with the requirements prescribed by UNI EN 12697-31, 4500 gr of HMA have been introduced into the mould during specimen preparation; however, to comply with the requirements fixed by UNI EN 12697-23, $3000 \mathrm{gr}$ of HMA was used.

\subsection{Laboratory phase results}

The ITS value has been evaluated on 7 specimens for each compaction process described above. The size of the specimen and different number of revolutions as reported in Table 5. Each specimen, before to test, was kept in an air chamber at $25^{\circ} \mathrm{C}$.

Fig. 4 reports the mean value of the ITS of each abovementioned combination. The figure shows that the ITS value is the same for G100B and G180B while there is a difference of $4 \%$ between G100A and G180A. Besides, after being conditioned in a water bath for $72 \mathrm{~h}$ at $40^{\circ} \mathrm{C}$, the specimen $\mathrm{G} 180 \mathrm{~B}$ seems not to affect any reduction in terms of ITS; while the other specimens show a reduction of 14, 20, 22 and 30\% respectively for Marshall, G100A, G180B and G180A. 
Table 5: Sample obtained from Marshall compaction and gyratory compaction.

\begin{tabular}{|c|c|c|c|c|}
\hline Label & Compaction Type & Height & $\mathrm{N}_{\text {design }}$ & $\mathrm{N}^{\circ}$ specimens \\
\hline MT & Marshall & $\mathrm{h} \in(63,5 \pm 2,5)$ & - & 7 \\
\hline G100A & Gyratory & $\mathrm{hmin} / \mathrm{D} \in(0.66 ; 1.05)$ & 100 & 7 \\
\hline G180A & Gyratory & $\mathrm{hmin} / \mathrm{D} \in(0.66 ; 1.05)$ & 180 & 7 \\
\hline G100B & Gyratory & $\mathrm{h} \in(35 \mathrm{~mm} ; 75 \mathrm{~mm})$ & 100 & 7 \\
\hline G180B & Gyratory & $\mathrm{h} \in(35 \mathrm{~mm} ; 75 \mathrm{~mm})$ & 180 & 7 \\
\hline
\end{tabular}

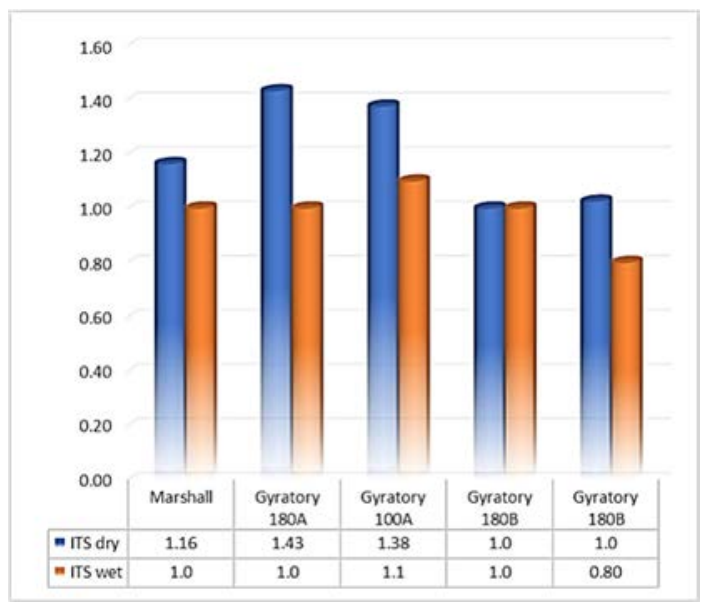

Figure 4: ITS wet and dry.

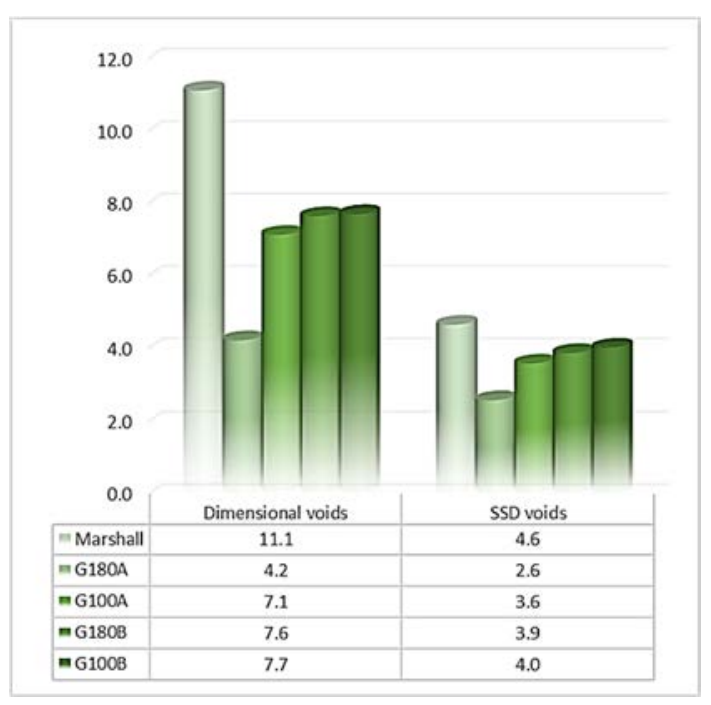

Figure 5: Relationships among geometric and imbibed voids in average values. 
At the same time, on the same specimens adopted for the ITS test air voids have been evaluated using SSD and dimensional procedures. The results show a difference about of $6.9 \%$ in terms of dimensional air voids between Marshall specimens and G180A. Instead the mixture G100A, G180B and G100B show approximately the same dimensional voids value. Nevertheless, the SSD voids are also different between specimens compacted through Marshall compactor and G180A with a difference of 2\%, instead G100A, G180B and G100B are the same.

\subsection{Statistical analysis validation}

As well as to clearly compare the properties of the various specimen types, a statistical analysis was performed to evaluate the significance of the differences among the properties. In the first place to verify that the data are distributed normally, the Kolmogorov-Smirnov (KS) test has been adopted. This type of test is also used to check the assumption of normality in Analysis of Variance. It compares the cumulative distribution function for a variable with a specified distribution. The test was carried out on ITS value of each type of combination described above. Table 6 shows the results of KS test and as it is possible that the critical value $\mathrm{Dn}$, critical, $\alpha$ equals to 0.48342 is always greater than $\mathrm{D}_{\mathrm{n}}$. In order to demonstrate the normal distribution of the date, the analysis of Variance (ANOVA) was carried out.

Table 6: KS test_RTI Normal distribution.

\begin{tabular}{|c|c|c|c|}
\hline Type & Dn value & Dn critical & $\begin{array}{c}\text { Normal } \\
\text { distribution }\end{array}$ \\
\hline Marshall & 0.25629 & & Verified \\
\hline G100A & 0.22159 & & Verified \\
\hline G180A & 0.30967 & \multirow{2}{*}{0.48} & Verified \\
\hline G100B & 0.14908 & & Verified \\
\hline G180B & 0.30754 & & Verified \\
\cline { 1 - 1 } & & \\
\hline
\end{tabular}

The ANOVA was conducted at $5 \%$ significance level $(\alpha=0.05)$, which means that for each comparison reported as being significantly different or not, there is only a $5 \%$ chance that it is not true. The results of a one-way ANOVA, to establish the difference between the group in analysis, considering only one variable, are reported in Table 7. It is shown that there is no statistical difference in terms of ITS before the soaked in water bath between the same size specimens compacted at different number of revolutions $(\mathrm{GB} 180=\mathrm{GB} 100$ and $\mathrm{G} 100 \mathrm{~A}=\mathrm{G} 180 \mathrm{~A}$ ).

Table 7: One-way ANOVA results.

\begin{tabular}{|c|c|c|c|c|}
\hline \multirow[b]{2}{*}{ Compaction Method } & \multicolumn{4}{|c|}{$\begin{array}{c}\text { LSD test; variable ITS }\left(\mathrm{N} / \mathrm{mm}^{2}\right) \\
\text { Homogenous Groups, alpha }=0.05000 \\
\text { ERROR: Between MS }=0.01087 \mathrm{df}=65,000\end{array}$} \\
\hline & Mean ITS $\left(\mathrm{N} / \mathrm{mm}^{2}\right)$ & 1 & 2 & 3 \\
\hline G180B & 0.967143 & $* * * *$ & & \\
\hline G100B & 1.021429 & $* * * *$ & & \\
\hline MARSHALL & 1.164286 & & & $* * * *$ \\
\hline G100A & 1.375714 & & $* * * *$ & \\
\hline G180A & 1.432857 & & $* * * *$ & \\
\hline
\end{tabular}




\section{CONCLUSION}

The principal characteristic of a road superstructure is to guarantee a mixture that should have high strength, to be capable of supporting heavy traffic loads without cracking or rutting. It is possibly highlighted that the duration of the useful life of a road pavement is precisely the resistance that the mixture is able to exert if subjected to strong stresses such as those due to road traffic.

For this reason, the evaluation of indirect tensile strength for each layer of a road flexible pavement, is one of the fundamental tasks that must be carried out in order to guarantee better performance in terms of stiffness and strength resistance.

Based on the experimental analysis, the following main conclusions could be drawn:

- Varying the type of compaction, the dimensional voids, SSD voids and ITS value changed. In particular, fixing the size of the specimen and varying the number of revolutions does not change the ITS, instead changing the size and fixing the number of revolutions changes the ITS.

- The ITS value is proportional to the air voids percentage. In particular if the ITS value grows, voids percentage (evaluated with both procedures) decrease. This correlation could be due to the different specimen densification; in particular the bulk density of specimens packaged according to UNI EN 12697-31 is higher than bulk density of specimens packaged according to UNI EN 12697-23.

- Statistically it is confirmed that varying the number of revolutions but fixing the size of the specimen does not make significant difference.

This present study had as purpose to achieve the optimum specimen size for the evaluating of the ITS parameter obtaining the same results in terms of voids for the optimum of the mixtures, obtained using Marshall test, with the gyratory compactor. From the results it was concluded that, for the determination of ITS value, there can be an assessment on mixture compacted according to ITS standard (UNI EN 12697-23) with a $\mathrm{N}_{\text {design }}=100$ revolutions.

\section{REFERENCES}

[1] Bocci, M. \& Giuliani, F., Caratterizzazione di filler per conglomerati bituminosi. XXIII AIPCR Convegno Nazionale Stradale, pp. 18-21, 1998.

[2] Veropalumbo, R., Viscione, N. \& Formisano, A., Hot mix asphalt with fly ashes for dense-graded surface Layers of rural roads. WIT Transactions on Ecology and the Environment, vol. 215, WIT Press, pp. 93-105, 2018.

[3] Sheng, Y., Zhang, B., Yan, Y., Chen, H., Xiong, R. \& Geng, J., Effects of phosphorus slag powder and polyester fiber on performance characteristics of asphalt binders and resultant mixtures. Construction and Building Materials, 141, pp. 289-295, 2017.

[4] Sangiorgi, C., Tataranni, P., Simone, A., Vignali, V., Lantieri, C. \& Dondi, G., Assessment of waste bleaching clay as alternative filler for the production of porous asphalts. Construction and Building Materials, 109, pp. 1-7, 2016.

[5] Sangiorgi, C., Tataranni, P., Simone, A., Vignali, V. Lantieri, C. \& Dondi, G., Assessment of waste bleaching clay as alternative filler for the production of porous asphalts. Construction and Building Materials, 109, pp. 1-7, 2016.

[6] Chen, M., Lin, J., Wua, S. \& Liu, C., Utilization of recycled brick powder as alternative filler in asphalt mixture. Construction and Building Materials, 25, pp. 1532-1536, 2011. 
[7] Pasetto, M. \& Baldo, N., Recycling of waste aggregate in cement bound mixtures for road pavement bases and sub-bases. Construction and Building Materials, 108, pp. 112-118, 2016.

[8] Hu, J., Liu, P., Wang, D., Oeser, M. \& Tan, Y., Investigation on fatigue damage of asphalt mixture with different air-voids using microstructural analysis. Construction and Building Materials, 125, pp. 936-945, 2016.

[9] Simone, A. et al., Experimental application of waste glass powder filler in recycled dense-graded asphalt mixtures. Road Materials and Pavement Design, pp. 1-16, 2017.

[10] Russo, F., Biancardo, S.A., Formisano, A. \& Dell'Acqua, G., Predicting percent air voids content in compacted bituminous hot mixture specimens by varying the energy laboratory compaction and the bulk density assessment method. Construction and Building Materials, 164, pp. 508-524, 2018. 